\title{
Hindsight bias and investment decisions making empirical evidence form an emerging financial market
}

Hussain, Muntazir $\gtrsim$

Shah, Syed Zulfiqar Ali

International Islamic University Islamabad, Pakistan (zulfiqar.shah@iiu.edu.pk)

Latif, Khalid

International Islamic University Islamabad, Pakistan (Khalidlatif382@yahoo.com)

Bashir, Usman

International Islamic University Islamabad, Pakistan (bbashir.usman@gmail.com)

Yasir, Muhammad

International Islamic University Islamabad, Pakistan (yasirfw@hotmail.com)

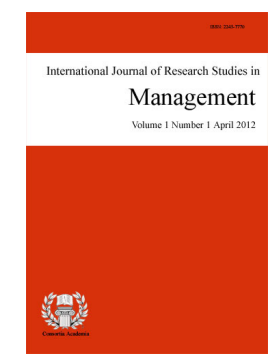

ISSN: $2243-7770$ Online ISSN: 2243-7789

OPEN ACCESS

\section{Abstract}

We studied the hindsight bias and investor decision making by employing the novel approach asset selection effect and sign of return effect. The study investigated the hindsight bias and investor decision making through questionnaires. The respondents are divided into three groups namely bank financial managers, stock market investors and students. The statistical significance of the asset selection effect and sign of return effect is tested by proportional z-test. Furthermore, the correlation of the memory error and recall error is also determined. The overall perceived error (hindsight bias) relationship is checked with the confidence in recall and confidence in estimate. We found strong evidence of hindsight bias in all respondents groups and its worst consequence on investment decision making. The bank financial managers were found less exposed to hindsight bias in comparison to stock market investors in asset selection effect. However, in sign of return effect the financial managers were more hindsight biased than the stock market investors. The relationship of hindsight bias and confidence in recall and confidence in estimate also confirms that all the respondents were hindsight biased and more confident in their estimate and less confident in their recall. All the respondents claim that they knew the phenomenon all along are wrong in their estimate. The respondents were unable to learn from previous errors and unable to detect their errors in estimate and recall. This error in prediction leads the investor to bear the risk above their accepted level which is harmful to their wealth.

Keywords: hindsight bias; asset selection effect; sign of return effect; estimate error; recall error; overall perceived error 


\section{Hindsight bias and investment decisions making empirical evidence form an emerging financial market}

\section{Introduction}

Since the emergence of behavioral finance two basic debates are the focus of researcher in the context of investment decision making. Are the investor rational and market are efficient? These are conflicting areas where behavioral finance contradicts with standard finance. Thaler (2005) argues that the contradiction in these subjects and question of rationality is raised based on two assumptions. The first assumption is that the investors are very much capable of absorbing and taking new information and set their selves accordingly. The investor decision is free of cognitive and emotional biases. The second assumption is the normality of investor choices. Nofsinger (2001) if the investor is rational and market is efficient then why the global financial crises 2008 and global recession happened where the major economist were failed to understand the nature of phenomena and unable to tackle the problem? The work of psychologists Daniel Kahneman and Amos Tversky (1974) has created the platform to apply the psychology to finance. The investors are not perfectly rational. The question of rationality was answered simple way, "the application of psychology to finance that we call the behavioral finance". The investment decisions are subject to cognitive and emotional biases that make the investor to take the worst decisions. Bernstein (1998) it is the impact of human cognitive and emotional errors that creates the bad decision and leads the investor to excessive risk. Parikh (2011) argues that the excessive risk the investors take due to the involvement of biases. These biases create mistakes and other investor takes advantage of these mistakes.

According to standard finance the investor are rational and market are efficient. The standard finance suggest that investment decision are determined by interest rates, income, consumption, level of economic activity, cost of capital goods, technological change, public policy, and many others. No doubt the investor the work of standard finance can't be ignored however, to check the balance approach of behavioral finance and standard finance would lead to better decision. Thus appealing approach to explain investment behavior practically is to consider the psychological factors that affect the investment decision. Pompian (2006) mentioned twenty two biases in his famous book "behavioral finance and wealth management" that effects investment decisions. In our study we have investigated one of the factors that effects the investment decision is called the Hindsight bias. This study was first conducted by Fischoff (1975) to define and analyze the hindsight bias. According to this study, person tendency to distort a previous judgment in the direction of the new information, after learning the real outcome of a situation or correct answer to question. Individuals after receiving final information claim to have known it all along. Once the event has passed, they seem more understandable and also more predictable than they seemed at the beginning.

In investment work we often face with the situation where we think that certain event is predictable even if it is not. Such events we often see in stock market investment. Where investor predicts certain stock would increase in value. Later on when the real event happens our prediction goes wrong and we come across excessive risk. Due to such irrational predictions we often see stock market crashes and boom. Such events may cause extraordinary losses to one investor and gain to other.

Learning from past experience and ability to recall is one of the basic approaches the investor follows while doing investment decisions. In order to invest, the investor search out the information and financial data. The data is arranged and transformed in meaningful way to carry the investment decision. In order to do so they perform various cognitive tasks and involve the memory recall process (Fischhoff, 1975). We are going to find whether this recall and cognitive process is free of omission and errors? How does the acquisition of final knowledge effect investment decisions? More formally whether the investors are hindsight biased or not and what is the impact of hindsight bias on investment decisions? 
Hindsight bias and investment decisions making empirical evidence form an emerging financial market

In psychological literature we can see three types of theories that explain the hindsight bias. The popular theories are named "Just World Theory", "Impression Management Theory", and "Cognitive Explanation Theory". The cognitive explanation theory is one of the most appropriate to explain the hindsight bias in the special case. That they people do wrong prediction of event or claim that they "Knew the event all along". They claim that event was predictable even if it was not. The errors in memory and recall cause the people to learn from their experience even after the realization is given.

According to economic theory investor are "Bayesian decision-makers" they assume that the investor update their information when they are presented the new information. They recall their initial information and update their information accordingly. The investors can recognize their error and learn from past and decide accordingly in future investment decisions. One of the fundamental assumptions in these theories is that the investors compare the new information with the previous expectation. They are able to compare the new and previous expectation. Economic theories suggest that arranged and transformed information the investor use for the purpose investment is free of omissions and errors. Furthermore, the investors are efficient in performing these cognitive tasks and easily manage this information. They also assume that the recall they made is error free. The similar assumptions are also followed by standard rational choice theory that states that the investors are efficient in determining relevant information and very much capable of separating the relevant information from irrelevant. Investors are able to process the information accurately. "The representative investor is assumed to understand the economy and the process determining asset prices; the individual investor frequently does not" (Keynes, 2006). However this is ideal case and practically these cognitive tasks and recall process involve the error and omission (Biais \& Weber, 2008).

One of the primary objectives of this study is to check empirically these recall errors and omission that lead to hindsight biasness. How the hindsight bias can impact investor decision making. How the final information can impact the investment decision. The study is of extreme significance it can lead the investor to take excessive risk. When the investment appreciate, hindsight biased investors tend to rewrite their own memories to portray the positive developments as if they were predictable. Over the time, this rationale can cause excessive risk taking. Furthermore, hindsight investors make incorrect forecast which can lead him to undiversified portfolios investment. The hindsight investor will lose the lesson to learn from past and show aggressive behavior in investment.

Our contribution lies in two aspects. First we have studied the practical respondents (Islamabad Stock Exchange Investors and Financial Managers of banks) where majority of literature related to Pakistan is taking only students as target respondents. Further, we have compared the biasness of students with the investors. We have incorporated the new angle of measuring the hindsight bias in two different aspects i.e., hindsight in asset selection, sign of return effect. We have applied Fischhoff (1975) procedure which is for the first time used to check hindsight bias in this context. Finally the study is organized in four different sections, the section 2 contains literature review, following by model and methodology is given in section 3, the results and conclusion is given in section 4 .

\section{Literature review}

Past experiences and data is one of the tools which investor use to predict the event happening in future. Most of investor feels confident to predict the future event to happen base on the personal erroneous cognition. Investor thinks that the event was predictable even if it was not. The investor take decision on such erroneous beliefs and cognition (biases) which leads them to bad decision. Such phenomenon is studied in behavioral finance and psychology literature called the hindsight bias. This bias effects the investment decision. Such evidence is quoted in literature in the following words.

Numerous studies have been conducted on impact of hindsight bias on investing decision. Like Tversky and Kahneman (1974a) stated that investor limited principles of life experiences are better to use but these can lead 
to biases in investment. One of the biases he studied is the hindsight bias which lead the poor investment performance. Biais and Weber (2008) studied the hindsight bias and concluded that hindsight biased investor the ex-post recollection of the initial belief will be closer to the realization than the true ex-ante expectation. Buksar and Conolly (1988) concluded that one should learn from past experience and should adjust oneself to the new situation but hindsight biased investors loose this learning and don't learn from past experiences.

In addition, Vein, Biais, and Weber (2008) studied hindsight bias and concluded that investors were not able to remember their initial answer (initial experience). This can lead the investors to poor performance of investment by underestimating the volatility. The level of exposure to these biases is dependent to other factors as well like gender, experience as well. Like Lewellen, Lease, and Schlarbaum (1977) men are more overconfident. Kaustia, Alho, and Puttonen (2008) concluded that the level of experience reduce the anchoring bias. Frederick (2005) stronger cognitive ability can enhance the investment decision making.

The first study conducted to check hindsight bias was (Fischhoff, 1975; Fischhoff \& Beyth, 1975). Fischhoff (1975) finds that receipt of outcome knowledge affects subject's judgments in the direction predicted by the tendency to perceive reported outcomes as having been relatively inevitable. This tendency was called as creeping determinism but is nowadays better known as hindsight bias. Fischhoff (1975) concludes that unperceived creeping determinism can seriously impair our ability to judge the past or learn from it. In a more recent study Biais and Weber (2008) present that for hindsight biased investor the ex-post recollection of the initial belief will be closer to the realization than the true ex-ante expectation. Such investors also fail to remember how ignorant they were before observing outcomes and answers. The hindsight biased people don't learn from past errors. The similar study was conducted by (Camerer, Loewenstein, \& Weber, 1989).

Hindsight bias is not affecting only in unconscious way, like in ex-post evaluation of ex-ante decision, but also when subject is aware of the bias. Buksar and Conolly (1988) find that student subjects working on a strategic choice case, both alone and in groups were unable to ignore what they had been told about the actual results of a choice. As a result, they distorted their evaluations of the original decision and the factors influencing it. Behavior caused by Hindsight bias is also recognized in studies observing other biases. Camerer et al. (1989) who study judgmental errors in economic settings, find that asymmetric information is not always beneficial for the better-informed agent, which violates the common assumption of economic analyses. This effect is known as curse of knowledge.

Camerer et al. (1989) noted the course of knowledge may also influence individual decision making under uncertainty. Exaggerating the predictability of events intensifies the regret people feel when choices yield outcomes worse than those that would have resulted from forgone options. This is in line with hindsight bias as people thinking behind this goes like I knew this would happen, why I did not act correctly. Baron and Hershey (1988) present the similar results that the course of knowledge suggests that outcome information will be overused; principals will tend to think that ex-ante optimal decisions with unfavorable outcomes were non-optimal and that non-optimal decisions with favorable outcomes were optimal. Camerer et al. (1989) suggest that investor will be excessively penalized for negative outcomes and insufficiently rewarded for favorable results.

Buksar and Conolly (1988) also presented that when outcomes are poor, then, people's evaluations of earlier decisions tend to be biased in an unflattering direction. "I should have known it all along they feel, puzzled at their poor decision making. Traditional way to justify market rationality is to state that even though some investors are irrational, markets in total are rational as the individual irrationalities are random and thus on average cancel each other out. Camerer et al., (1989) found that hindsight bias in markets was half as large as bias in individual judgments. Their data suggest that the error-correcting power of markets derives not from the feedback they provide, but from the disproportionate activity of more rational traders. Hindsight bias is also affecting performance evaluation in principal agent relation. (Mangelsdorff \& Weber, 1998; Madarasz, 2008) shows that, in a principal agent relationship, the hindsight bias will prevent the principal from correctly 
Hindsight bias and investment decisions making empirical evidence form an emerging financial market

evaluating the performance of the agent. Biais and Weber (2008) tested the hindsight bias and come to conclusion that biased principals fail to remember what was known when the agent's decision was taken.

Measuring the level other psychological factors and its relationship with the hindsight bias are also studied in the literature. Bradley (1981) concluded that expertise and high level of knowledge reduce hindsight bias. Another factor that reduces hindsight bias is the strong cognitive ability. Lubinski and Humphreys (1997) the person with high cognitive ability and intelligence perform best investment decision. Such person has strong memory power and may reduce hindsight bias. Frederick (2005) tested the subjects on the basis of cognitive reflection test and concluded that the subjects with higher cognitive ability proved better investment decisions. In literature we see different test for measuring the cognitive ability and expertise.

Tversky and Kahneman (1983) divide the information processing system into two parts: Interactive system and Experimental System. Epstein (1996) used separate test to check the cognitive ability by rational experimental inventory. This test checks both the analytical abilities and intuitive experimental processing. Cacioppo and Petty (1982) used Need for cognition scale to measure the analytical abilities. Cacioppo (1996) presented that the people with high need of cognition are better informed and have greater capability of information processing and less exposed to hindsight bias. The second aspect of psychological factor that is intuitive ability is also narrated by literature and named it as "Intuitive Experimental Processing", which is normally measured on the scale of "Faith in Intuition" concluded that people with high score (Faith in Intuition) are more exposed to hindsight bias (Tversky \& Kahneman, 1974b; Epstein, 1996).

Due to vital importance of the impact of this phenomenon is still hot topic of research. Such phenomenon is studied in other fields like auditing, businesses ethics, court decisions, and many others, and its impact in different situation. The evidence can be found the studies of (Roese \& Vohs, 2010; Pezzo \& Beckstead, 2008; Mueller \& Stahlberg, 2007; Nestler \& Egloff, 2009; Lowe \& Reckers, 2000; Anderson, Jennings, Lowe, \& Reckers, 1997; Gilibert \& Banovic, 2009; Wasieleski, Whatley, \& Murphy, 2009; Annunziata, 2009; Sligo \& Stirton, 1998; Wallace, Chang, Carroll, \& Grace, 2009).

The most recent studies incorporate the short rum aspect of decision. Some studies have studied the impact of hindsight on short term decision. Tchai (2012) studied the impact of hindsight bias on short term investment found it significant that hindsight bias distort investment decision and investor take excessive risk due to erroneous predictability of event. Goodwin (2010) studied the same phenomenon and divides the sample into three categories, stock broker, students and professional concluded that professional were exposed to such bias. The experience was the main factor that provides the immune to avoid such bias. Pompian (2006) studies this phenomenon and concluded that the hindsight bias causes the investor to take excessive risk by considering that the event is predictable even if it was not. Pezzo and Pezzo (2007) studied the phenomenon and argued that the investors are not even prepared to accept the reality that they can't predict the event. If they are given the true result they would claim that they predicted the true event. They are superior in prediction and they can predict. He concluded that such investment behavior distorts the investment decision and caused investor to take risk that is beyond their limits. As for as the literature relating to this specific study is conducted to check the impact of hindsight bias on investment decision; the study is an attempt to check the phenomenon with respect to Pakistan.

\section{Data and research methodology}

\subsection{Data}

The data is collected by questionnaire by targeting students major in Finance and financial Manger of banks and stock market investors. The 55 students, 89 financial managers, and 56 stock market investors are taken as sample. The total sample is 200 . The questionnaire is distributed in two phases with one weak interval between phases. In first phase of questionnaire the target respondents given questions related to background information like age, sex and field experience and ten questions related to individual thinking style which are measured on 
Hussain, M., Shah, S. Z. A., Latif, K., Bashir, U., \& Yasir, M.

five scales. Further the respondents are asked to estimate return of asset based on graph. In return estimation task the respondents are asked to choose better performance asset. In this assignment the strength of view measured on five scales. The respondents were instructed to estimate the return of asset on $95 \%$ confidence limit. The second phase is the memory recall phase where respondents were instructed to recall their initial answer and classify how well they can recall. The answer and return estimate are recollected. Furthermore, in the second phase the target respondents are given again the same return estimation task with updated information to check how well they learn from previous experience and how they adjust to new updated information.

\subsection{Measurement of Hindsight Bias}

Fischoff (1975) methodology to measure and its impact on investment decisions was used in this study. The hindsight bias is measured in two different context i.e. Asset selection effect, sign of return effect.

\section{Hindsight Bias in Asset selection}

If people are given two choices to select better performing asset (as we did) also called winner asset, the people will remember their initial choice incorrectly and if they are presented the true result the biased investor will remember that they chose the winner asset which may not true. The basic reason behind this test is the biased investor are not able to detect that they have choose the wrong choice in case of winning asset (better performing asset). This over-estimation is measured by comparing the proportion of correct answers and respective remembered proportion. This data is available by initial selection, recollection of initial selection and realized results of questionnaire. The proportions Z-test is used to check the statistical significance of difference between true and remembered proportions of successful answers.

$$
\begin{gathered}
z=\frac{p 1-p 2}{S p 1-p 2} \ldots \ldots \ldots \ldots(1) \\
S p 1-p 2=\sqrt{\frac{p(1-p)}{n 1}}+\sqrt{\frac{p(1-p)}{n 2}} \ldots \ldots \ldots(2) \\
p=\frac{n 1 p 1+n 2 p 2}{n 1+n 2} \ldots \ldots \ldots \ldots \ldots \ldots(3)
\end{gathered}
$$

Where $\mathrm{p}_{1}=$ true proportion of successful answers

$\mathrm{p}_{2}=$ the proportion of respondents who believe they answered correctly

$\mathrm{n}_{1}$ and $\mathrm{n}_{2}=$ sample sizes

\section{Hindsight Bias in Sign of Return Recall}

As we have given the questionnaire where the respondent to assign the sign to return they think that winning asset (better performing asset). The sign of return can either be positive or negative which respondent have to remember that sign which they responded in first phase of questionnaire. Hindsight biased investors normally remember the initial sign assigned to the return incorrectly. When hindsight biased investors are presented the true sign of estimated return they think that they have assigned correct sign which may not be the case. The test logic is same as we applied to asset selection test but here our focus on sign instead of asset selection. Here the overestimation of one's success detected by comparing the actual proportion of correctly estimated sign of return and respected remembered proportion. To test the statistical significance of difference between true and remembered proportion correct sign of return, we use the proportional z-test. The procedure is same as asset selection effect but only difference is the sign of return instead of asset selection. 
Hindsight bias and investment decisions making empirical evidence form an emerging financial market

\subsection{Estimate and Memory Error}

$>\quad$ The error in estimate is measured by difference of original estimate in first phase and real outcome (true answers)

$>\quad$ The error in memory recall is measured by difference of recalled estimates in phase 2 and originally given in phase 1

$>\quad$ The correlation of two errors (memory and estimate error)

$>\quad$ Correlation between confidence and memory errors

Relationship between overall perceived error (hindsight bias) and error in estimate and error in recall is given by

$$
H=\alpha+\beta_{1} C E+\beta_{2} C R+\varepsilon
$$

Where " $\mathrm{H}$ " is hindsight bias, "CE" is confidence in estimate and "CR" is confidence in recall.

\section{Results}

\subsection{Hindsight Bias in Asset Selection}

The table 1 below shows the hindsight bias in asset selection effect. The true and remembered proportions are calculated and their statistical significance is checked by proportional z-test. The $95 \%$ confidence interval is used for level of significance. Our hypothesis is that the difference of two proportions is 0 , means that there is no hindsight bias. Where the difference proportion is in alternative hypothesis is not zero, means the respondents are hindsight biased. The data analysis is divided into three groups for analysis purpose i.e. bank financial managers, stock market investors and students. The z-statistics is given in parenthesis.

\section{Table 1}

Hindsight Bias and Asset Selection Effect

\begin{tabular}{lcrr}
\hline & True Proportion & Remembered Proportion & $\begin{array}{c}\text { Error= Difference of true } \\
\text { and remembered }\end{array}$ \\
\hline Bank Finance Managers & 0.63 & 0.67 & 0.04 \\
Stock Market Investors & $(\mathrm{N}=166)$ & $(\mathrm{N}=158)$ & $(0.72)$ \\
Students & 0.44 & 0.59 & $0.15^{* * *}$ \\
& $(\mathrm{~N}=258)$ & $(\mathrm{N}=107)$ & $(2.62)$ \\
& 0.45 & 0.55 & $0.1^{* *}$ \\
\hline
\end{tabular}

Note. $* p$ Value significant at $5 \%$. ** $p$ Value significant at $10 \%$

In case of all respondents there is error in true and remembered proportions but z-statistics is not significant in all the categories. The stock market investors are highly hindsight biased where the difference is 0.15 and highly significant at $95 \%$ level of significance. The results are in accordance to literature where the stock market investors are more exposed to hindsight bias. One of example is stock market bubble and crashes in 1990 and 1920 in American stock exchanges. We found the less evidence of hindsight bias in bank financial managers which is also not significant. Furthermore the students are more hindsight biased which is also significant. The students' hindsight bias is to less experience in field of financial decision and knowhow of financial decisions. Whereas the bank financial managers are highly experienced and related to private sector banks are less exposed to hindsight bias.

One of the factors that could explain the less hindsight bias in bank financial managers is their expertise 
Hussain, M., Shah, S. Z. A., Latif, K., Bashir, U., \& Yasir, M.

level. As we found in literature that hindsight bias is reduced by level of expertise. Second reason the bank financial manager is less exposed to hindsight bias is the private ownership and audit system in Pakistan. In private banking sector of Pakistan the true audit measure and true responsibility towards the bank operation and minimum chances of error is expected by the owners.

\subsection{Hindsight Bias in Sign of Return Effect}

The test procedure is same for the sign of return effect. The true and remembered proportion of sign of return is tested by proportional Z-test. The level of significance is $95 \%$. The test results are given below.

Table 2

Hindsight Bias and Sign of Return Effect

\begin{tabular}{lcrr}
\hline & $\begin{array}{c}\text { True Sign Assigned } \\
\text { Proportion }\end{array}$ & $\begin{array}{c}\text { Remembered Sign } \\
\text { Assigned Proportion }\end{array}$ & $\begin{array}{c}\text { Error= Difference of the } \\
\text { two }\end{array}$ \\
\hline Bank Financial Managers & 0.11 & 0.23 & $0.12 * * * *$ \\
& $(\mathrm{~N}=166)$ & $(\mathrm{N}=121)$ & $(2.64)$ \\
Stock Market Investors & 0.19 & 0.26 & 0.07 \\
& $(\mathrm{~N}=145)$ & $(\mathrm{N}=65)$ & $(1.12)$ \\
Students & 0.24 & 0.23 & 0.1 \\
& $(\mathrm{~N}=117)$ & $(\mathrm{N}=78)$ & $(0.14)$ \\
\hline
\end{tabular}

Note. $* p$ Value significant at $5 \%$. ${ }^{* *} p$ Value significant at $10 \%$

The results in table 2, shows that the bank financial managers are more exposed to the hindsight bias in sign of return task. This is statistically significant at $95 \%$ level of significance. The investors and students are less exposed to hindsight bias in sign of return task. One conclusion we can draw that the bank financial managers were more exposed to erroneous prediction of sign of return.

\subsection{Correlation in Estimate Error and Recall error and Regression Results}

The data has divided into three parts on the basis three main categorize of respondents that is financial managers, stock market investors and students. The correlation is measured on the basis of estimate error and memory recall error for each respondents group. The correlation between the estimate error and memory recall error is $0.7955,0.60$ and 0.69 for financial managers, stock market investors and students respectively. Confirming that increase of one error is increasing the other error. The regression results as expected the coefficients of (CE) is positive and (CR) is negative confirming the strong hindsight bias. The respondents are more confident in estimation as predicted in literature. The hindsight biased responder will have overconfidence in estimate as "I knew it all along" and unconfident in recall.

\section{Conclusion}

The study presents the cognitive explanation of investment decision making. The hindsight bias and its impact are measured in two different aspects that is hindsight bias in asset selection and sign of return. The study is conducted in two phases by dividing the sample into three main groups, i.e. bank financial managers, stock market investors and students. The hindsight bias is measured in by comparing the true and recalled estimates of questions in different phases of survey. The difference is called the "error" or hindsight bias whose significance is checked by proportional z-test. Furthermore the correlation is checked among different error to check the relationship of one error with other. Finally the regression results are given to note the overall perceived error (hindsight bias) and its relationship with the confidence in recall and confidence in estimate.

In two different aspects of hindsight bias (asset selection effect and sign of return effect) the three groups (banks financial Mangers, Stock Market Investors and Students) are hindsight biased. However, we found strong impact of hindsight bias in asset selection effect that stock market investor are more exposed to the hindsight bias, whereas, in sign of return effect the bank financial managers are more exposed to hindsight effect. In both 
scenarios the respondents had given the wrong estimate and predictions by exposing themselves to bear higher risk. They think that they knew the phenomenon all along which is not the case. The respondents were unable to learn from previous errors when they were given true results; confirming that the hindsight bias respondents are unable to learn from their previous experiences. In real investment scenario the investor will bear the excessive risk by saying "I knew it along".

Finally the correlation and regression results confirm that the respondents are hindsight biased and more confident in their estimate and unconfident in their recall confirming the strong evidence of hindsight bias. Where the hindsight biased respondent claim that he know the phenomenon all along which is not the case and bear the over-optimal risk which is harmful in real life investment.

\subsection{Recommendations}

The recommendations are presented to minimize the hindsight bias not to remove completely. The hindsight bias can be overcome by continuous education. To educate the investor to council before they go for major predictions. The investor may council advisors. Most of hindsight biased investor argues that the positive outcome of the event was predictable. To avoid this mistake that they will predict the same outcome in future is mistake. Put the real grounds of available data in consideration. The proper fundamental and technical analysis is recommended before taking any step of stock investment. The temporary increase or decrease can be deceptive and it is needed to check all available information before any forecast is made. Don't rely only on your prediction powers.

The advisor should be counseled when investor think that "I knew it all along" that this would happen in future. To avoid past investment mistake the advisor must remind the investor the past experience with the investor bad decision. Take the all available information resource to judge your decision. The fear of future loss may cause the investor to run from market and lose the available opportunity. The predicted loss may be able to be turned to profit if proper analysis is made. If the analysis of information suggests to not going for the investment then investor should leave otherwise take decision. Concluding the recommendation the proper education for the investor is essential and investor must consider the fundamental and technical analysis and all available information resource to predict the future loss or gain.

\subsection{Practical applications}

The phenomenon is of practical importance especially for the stock market investors. This behavior of investor causes the stock market bubble and crashes. The investors think that event is predictable even if it was not predictable. They take risk beyond their optimal by predicting certain activity. They did not take the appropriate information. They did not update their information and hence loose important information and expose themselves to risk. If we recall US stock market and investor behavior during 1993; 2003 we would see that investor predictions were wrong related to the increased stock prices. The temporary stock bubbles were associated with future increase in stock prices; the investor loose badly after the erroneous prediction. The investors who are victim of such bias think that they can predict the future market trends better than other. Such belief causes the investor to take bad decision regarding investing in stocks. The investor invests aggressively and under estimate the risk.

The investor victim of such bias may not able to learn from past errors as they even don't want to recall their previous experiences. If there is temporary boom in the market the hindsight investor may predict that future stock prices will appreciate and hold the losing stocks for the sake of profits which they feels may increase in future. Furthermore this temporary appreciation in stock prices may inspire the hindsight biased investor to admire their money manager for their good performance which is not due to their efforts. This admiration may cause the money manager to act aggressively. The well-known example of such event is "aggressive growth tech fund in 1990. Conversely the hindsight investor may blame the good manager for the poor performance. It is 
Hussain, M., Shah, S. Z. A., Latif, K., Bashir, U., \& Yasir, M.

might possible that poor performance is not due to their managerial skills. The famous example of such activity is "Small cap Value Fund Managers".

\subsection{Future direction of research}

So far we have tested the hindsight bias in two different angles that is hindsight bias in asset selection effect and sign of return effect. The further research could be done to search whether the hindsight bias is reduced with the level of expertise? Introduce the expertise as new variable and to check its impact on hindsight bias while dealing in investment decisions. Furthermore as overconfidence bias where the investor is victim of prediction over-confidence and certainty over-confidence and more close to hindsight bias can be studied to check the possible impact of over-confidence and hindsight bias with introducing the level of expertise as additional variable.

\section{References:}

Anderson, J. C., Jennings, M. M., Lowe, D. J., \& Reckers, P. M. J. (1997). The mitigation of hindsight bias in judges evaluation of auditor decisions. Journal of Practice \& Theory, 16, 20-39.

Annunziata, A. (2009). Retrospective bias in expert evidence: Effects on patient and doctor safety. Emergency Medicine Australasia, 21, 80-83. http://dx.doi.org/10.1111/j.1742-6723.2009.01155.x

Bradley, J. (1981). Overconfidence in ignorant experts. Bulletin of the Psychonomic Society, 17, 82-84.

Bukszar, E., \& Connolly, T. (1988). Hindsight bias and investment performance. Working Paper \# 476 IDEI Telehouse.

Bernstein, P. L. (1998). Against the Gods: The remarkable story of risk. USA: John Wiley \& Sons Inc.

Camerer, C. F., Loewenstein, G., \& Weber, M. (1989). The curse of knowledge in economic settings: Experimental analysis. Journal of Political Economy, 97, 1232-1254. http://dx.doi.org/10.1086/261651

Cacioppo, J. T., Petty, R. E., Feinstein, J. A., \& Jarvis, W. B. G. (1996). Dispositional differences in cognitive motivation: The life and times of individuals varying in need for cognition. Psychological Bulletin, 119(2), 197-253. http://dx.doi.org/10.1037/0033-2909.119.2.197

Cacioppo, J. T., \& Petty, R. E. (1982). The need for cognition. Journal of Personality and Social Psychology, 42(1), 116-131. http://dx.doi.org/10.1037/0022-3514.42.1.116

Epstein, S., Pacini, R., Denes-Raj, V., \& Heier, H. (1996). Individual differences in intuitive-experiential and analytical-rational thinking styles. Journal of Personality and Social Psychology, 71(2), 390-405. http://dx.doi.org/10.1037/0022-3514.71.2.390

Fischhoff, B. (1975). Hindsight foresight: The effect of outcome knowledge on judgment under uncertainty. Journal of Experimental Psychology: Human Perception and Performance, 1(3), 228-299. http://dx.doi.org/10.1037/0096-1523.1.3.288

Fischhoff, B., \& Beyth, R. (1975). I knew it would happen remembered probabilities of once future things. Organizational behavior and Human Performance, 13, 1-16. http://dx.doi.org/10.1016/0030-5073(75)90002-1

Frederick, S. (2005). Cognitive reflection and decision making. Journal of Economics Perspectives, 19(4), 25-42. http://dx.doi.org/10.1257/089533005775196732

Gilibert, D., \& Banovic, I. (2009). Effect of training in psychology on the causal interpretation of a clinical case. European Journal of Psychology of Education, 24, 373-385. http://dx.doi.org/10.1007/BF03174767

Goodwin, P. (2010). Why hindsight can damage foresight. The International Journal of Applied Forecasting, 17, 5-7.

Keynes, J. M. (2006). General theory of employment, interest and money. Atlantic Publishers.

Lewellen, W. G., Lease, R. C., \& Schlarbaum, G. G. (1977). Pattern of investment strategy and behavior among individual investors. Journal of Business, 50(3), 296-333. http://dx.doi.org/10.1086/295947

Lubinski, D., \& Humhreys, L. (1997). Incorporating general intelligence into epidemiology. Intelligence, 24(1), 
Hindsight bias and investment decisions making empirical evidence form an emerging financial market

159- 201. http://dx.doi.org/10.1016/S0160-2896(97)90016-7

Lowe, D. J., \& Reckers, P. M. J. (2000). The use of foresight decision aids in auditors judgments. Behavioral Research in Accounting, 12, 97-118.

Madarasz, K. (2008). Information projection: Model and applications. Working Paper, Berkeley.

Mangelsdorff, L., \& Weber, M. (1988). Hindsight bias in principal agent context. The Organization Changing Markets, 25, 461-678.

Mueller, P., \& Stahlberg, D. (2007). The role of surprise in hindsight bias: A meta-cognitive model of reduced and reversed hindsight bias. Social Cognition, 25, 165-184. http://dx.doi.org/10.1521/soco.2007.25.1.165

Nestler, S., \& Egloff, B. (2009). Increased or reversed? The effect of surprise on hindsight bias depends on the hindsight component. Journal of Experimental Psychology: Learning, Memory, and Cognition, 35(6), 1539-1544. http://dx.doi.org/10.1037/a0017006

Nofsinger, J. R. (2001). Investment madness: How psychology affects your investing and what to do about it. USA: Pearson Education.

Pezzo, M., \& Pezzo, S. P. (2007). Making sense of failure: A motivated model of hindsight bias. Social Cognition, 25(1), 147-165. http://dx.doi.org/10.1521/soco.2007.25.1.147

Pezzo, M., \& Beckstead, J. (2008). The effects of disappointment on hindsight bias for real world outcomes. Applied Cognitive Psychology, 22, 491-506. http://dx.doi.org/10.1002/acp.1377

Pompian, M. (2006). Behavioral finance and wealth management. Hoboken, NJ: Wiley.

Parikh, P. (2011). Value investing and behavioral finance. New Delhi: Tata Mcgraw Hill.

Roese, N., \& Vohs, K. (2010). The visualization trap. Harvard Business Review, 88(5), 26.

Sligo, P., \& Stirton, N. (1998). Does hindsight bias change perceptions of business ethics. Journal of Business Ethics, 17, 111-124. http://dx.doi.org/10.1023/A:1017946415414

Tchai, T. (2012). The hindsight bias effect in short-term investment decision-making. Universal Journal of Management and Social Sciences, 2(11), 201-212.

Thaler, R. H. (2005). Advances in behavioral finance, Vol. II. USA: Princeton University Press.

Tversky, A., \& Kahneman, D. (1974a). Judgment under uncertainty: Heuristics and biases. Science, 185, 1124-1130. http://dx.doi.org/10.1126/science.185.4157.1124

Tversky, A., \& Kahneman, D. (1974b). Extensional versus intuitive reasoning: The conjunction fallacy in probability judgment. Psychological Review, 90, 293-315. http://dx.doi.org/10.1037/0033-295X.90.4.293

Vein, B. J., \& Hershey, J. C. (1988). Outcome bias in decision evaluation. Journal of Personality and Social Psychology, 54, 569-579. http://dx.doi.org/10.1037/0022-3514.54.4.569

Wallace H. M., Chang, M., Carroll, P. J., \& Grace, J. (2009). I knew it all along, unless I had to work to learn what I know. Basic and Applied Social Psychology, 31, 32-39. http://dx.doi.org/10.1080/01973530802659844

Wasieleski M.., Whatley, M., \& Murphy, S. (2009). The hindsight bias and attitudes toward police deception in eliciting confessions. North American Journal of Psychology, 11, 285-296. 
Hussain, M., Shah, S. Z. A., Latif, K., Bashir, U., \& Yasir, M. 